CLINICAL STUDY

\title{
Fifteen years of GH replacement increases bone mineral density in hypopituitary patients with adult-onset GH deficiency
}

\author{
Mariam Elbornsson, Galina Götherström, Ingvar Bosæus ${ }^{1}$, Bengt-Åke Bengtsson, Gudmundur Johannsson and \\ Johan Svensson \\ Department of Endocrinology, Institute of Medicine, Sahlgrenska Academy, Sahlgrenska University Hospital, University of Gothenburg, Gröna Stråket 8 , \\ SE-413 45 Göteborg, Sweden and ${ }^{1}$ Department of Clinical Nutrition, Sahlgrenska University Hospital, SE-413 45 Göteborg, Sweden
}

(Correspondence should be addressed to M Elbornsson; Email: mariam.elbornsson@medic.gu.se)

\begin{abstract}
Objective: Few studies have determined the effects of more than 5-10 years of GH replacement in adults on bone mineral content (BMC) and bone mineral density (BMD).

Design/patients: In this prospective, single-centre, open-label study, the effects of 15 years of GH replacement on BMC and BMD, measured using dual-energy X-ray absorptiometry, were determined in 126 hypopituitary adults (72 men) with adult-onset GH deficiency (GHD). Mean age was 49.4 (range 22-74) years at the initiation of the study.

Results: The mean initial GH dose of 0.63 (s.E.M. 0.03) mg/day was gradually lowered to 0.41 (0.01) $\mathrm{mg}$ /day after 15 years. The mean serum IGF1 SDS increased from $-1.69(0.11)$ at baseline to 0.63 $(0.16)$ at the study end $(P<0.001$ vs baseline). The 15 years of GH replacement induced a sustained increase in total body BMC $(+5 \%, P<0.001)$ and BMD $(+2 \%, P<0.001)$. Lumbar (L2-L4) spine BMC increased by $9 \%(P<0.001)$ and BMD by $5 \%(P<0.001)$. In femur neck, a peak increase in BMC and BMD of 7 and $3 \%$, respectively, was observed after 7 years (both $P<0.001$ ). After 15 years, femur neck BMC was $5 \%$ above the baseline value $(P<0.01)$, whereas femur neck BMD had returned to the baseline level. In most variables, men had a more marked response to GH replacement than women. Conclusions: Fifteen-year GH replacement in GHD adults induced a sustained increase in total body and lumbar (L2-L4) spine BMC and BMD. In femur neck, BMC and BMD peaked at 7 years and then decreased towards baseline values.
\end{abstract}

European Journal of Endocrinology 166 787-795

\section{Introduction}

Young adults with GH deficiency (GHD) have reduced bone mineral content (BMC) and bone mineral density (BMD) $(1,2,3,4)$. This reduction in BMC and BMD is more marked in patients with childhood-onset (CO) GHD than in patients with adult-onset (AO) GHD (5). Elderly GHD adults do not have a reduced bone mass and density compared with age-matched healthy controls $(6,7)$. However, adult GHD patients without $\mathrm{GH}$ replacement are at a higher risk of fractures than healthy controls of the same age $(8,9,10)$. It is therefore possible that other factors than reduced BMD, such as increased number of falls due to visual deficits caused by pituitary tumours or their treatment, could contribute to the increased fracture risk in GHD adults.

Initiation of $\mathrm{GH}$ replacement in adults with GHD induces an initial increase in bone resorption that may result in unchanged or even reduced bone mass $(2,3)$. This is followed by increased bone formation and a net increase in bone mass seen after 12-18 months of $\mathrm{GH}$ replacement $(2,3)$. GH exerts direct effects on bone
$(2,11)$, but it has been questioned whether the direct effects can fully explain the effects of $\mathrm{GH}$ on bone. Indirect effects, such as increased muscle performance by GH, could also be of importance (12). Furthermore, the responsiveness to $\mathrm{GH}$ replacement is dependent on the group of patients studied. The increase in BMC and BMD is larger in patients with CO GHD compared with patients with AO GHD (5) and also more marked in men compared with women $(13,14,15,16,17,18)$. Finally, the response to $\mathrm{GH}$ is most marked at weight-bearing locations and the increase in BMC is greater than that of $\operatorname{BMD}(15,17)$.

GH replacement has been shown to induce a progressive increase in bone mass and density up to $5-6$ years of treatment $(15,19,20,21)$. One study of 7 years of $\mathrm{GH}$ replacement showed an increase in BMC and BMD up to 4 years and after that BMC and BMD reached a plateau (13). In another study, total body and lumbar (L2-L4) spine BMD and BMC increased progressively up to 10 years of $\mathrm{GH}$ replacement, whereas femur neck BMC and BMD reached a peak value after 5-7 years of treatment (22). 
Table 1 Causes of pituitary deficiency in the study population of 126 adults with adult-onset GH deficiency.

\begin{tabular}{lccc}
\hline $\begin{array}{l}\text { Causes of pituitary } \\
\text { deficiency }\end{array}$ & Men $(n)$ & Women $(n)$ & Total $(n)$ \\
\hline Pituitary adenoma & & & \\
Non-secreting & 44 & 22 & 66 \\
Secreting & 11 & 13 & 24 \\
Craniopharyngioma & 7 & 6 & 13 \\
Empty sella & 3 & 4 & 7 \\
Sheehan's syndrome & 0 & 3 & 3 \\
Idiopathic & 0 & 2 & 2 \\
Other pathology & 7 & 4 & 11 \\
Total & 72 & 54 & 126 \\
\hline
\end{tabular}

${ }^{a}$ One patient with a meningioma, two with pituitary apoplexia, one with histiocytosis X, two with sarcoidosis, one with a cholesteatoma, one with an ependymoma, one with a dysgerminoma and two with trauma.

GHD in adults is a chronic disease and $\mathrm{GH}$ replacement may therefore continue over decades. Long-term studies on the effects of $\mathrm{GH}$ treatment are therefore important. There are at present no studies of more than 10 years of GH replacement. The aim of this study was to investigate the effects of 15 years of $\mathrm{GH}$ replacement therapy on BMC and BMD in patients with AO GHD recruited at a single centre.

\section{Patients and methods}

\section{Patients}

In this study, 126 consecutive GHD adults (72 men) with a mean age of 49.4 (range 22-74) years were included between 1990 and 1994. All patients had AO pituitary disease and all had known pituitary disease or other anterior pituitary hormonal deficiencies. The pituitary deficiency was mainly caused by pituitary tumours and/or their treatment (Tables 1 and 2). The patients had been treated with pituitary surgery $(n=49)$, surgery and radiotherapy $(n=49)$, radiotherapy alone $(n=11)$ and no treatment $(n=17)$.

Most patients had multiple anterior pituitary hormonal deficiencies (Tables 1 and 2). Possibly due to late effects of radiotherapy, several patients had more pituitary hormonal deficiencies at study end compared with baseline (Tables 1 and 2). In 116 of the patients, the diagnosis of GHD was based on a peak $\mathrm{GH}<3 \mu \mathrm{g} / \mathrm{l}$ during a stimulation test (insulin $(n=112)$, GHRH $(n=2)$ and glucagon $(n=2))$. In nine patients, the diagnosis was based on a 24-h GH profile (sampling every $30 \mathrm{~min})$. In one patient, who had a known anterior pituitary disease and three additional hormonal deficiencies, the diagnosis was based on a low serum insulin-like growth factor 1 (IGF1) level. When required, patients received adequate and stable therapy with glucocorticoids, thyroid hormone and desmopressin. All the testosterone-deficient men received testosterone therapy. However, at baseline 52\% (25 out of 48 ) and at study end $31 \%$ (15 out of 48 ) of the oestrogen-deficient women received oestrogen replacement therapy. Five patients received treatment with vitamin $\mathrm{D}$, calcium and/or bisphosphonates after 5 $(n=1), 11(n=1)$ and $13(n=3)$ years of $\mathrm{GH}$ replacement. In these patients, the measurements performed after the initiation of treatment with vitamin $\mathrm{D}$, calcium and/or bisphosphonates were excluded in the statistical analysis, and the last value before treatment was carried forward according to the intention-to-treat approach used.

Fourteen of the patients died during the study period (cerebral infarction $(n=3)$, myocardial infarction $(n=2)$, pneumonia $(n=2)$, sudden death of unknown cause $(n=1)$, renal cancer $(n=1)$, subarachnoid haemorrhage $(n=1)$, chronic obstructive pulmonary disease $(n=1)$, perimyocarditis $(n=1)$, pulmonary embolism $(n=1)$ and coronary artery disease $(n=1))$. Fourteen patients discontinued GH replacement (lack of compliance $(n=7)$, old age $(n=3)$, colon cancer $(n=1)$, epilepsy after stroke $(n=1)$, pulmonary cancer $(n=1)$ and chronic lymphocytic leukaemia $(n=1))$. Eight patients were lost to follow-up because they moved to other cities or abroad. Thus, 90 of the 126 patients completed the 15 years of GH replacement. All patients were, however, retained in the statistical analysis according to the intention-to-treat approach used.

\section{Study protocol}

This is an ongoing, prospective, open-label treatment trial. The first 64 patients initially received a weightbased $\mathrm{GH}$ dose of $11.9 \mu \mathrm{g} / \mathrm{kg}$ per day $(0.25 \mathrm{IU} / \mathrm{kg}$ per week). During the first 2-3 years of treatment, the GH dose was gradually lowered and individualised when the weight-based dose regimen was abandoned. In the remaining 62 patients, the dose of $\mathrm{GH}$ was individualised from the initiation of the treatment, with the aim of normalising serum IGF1 concentration and body composition in each patient.

At baseline, and after each year of GH replacement until 5 years, and then after 7, 10, 12 and 15 years, physical and laboratory including measurements of bone mass examinations were performed. Dose titration

Table 2 Number of pituitary deficiencies at baseline and after 15 years of $\mathrm{GH}$ replacement (study end) in the study population of 126 adults with adult-onset GH deficiency (GHD).

\begin{tabular}{|c|c|c|c|c|c|c|}
\hline \multirow{2}{*}{$\begin{array}{l}\text { Type of } \\
\text { deficiency }\end{array}$} & \multicolumn{3}{|c|}{ Baseline $(n)$} & \multicolumn{3}{|c|}{ Study end $(n)$} \\
\hline & Men & Women & Total & Men & Women & Total \\
\hline Isolated GHD & 7 & 2 & 9 & 3 & 1 & 4 \\
\hline \multicolumn{7}{|l|}{$\begin{array}{l}\text { No. of additional } \\
\text { deficiencies }\end{array}$} \\
\hline 1 & 7 & 9 & 16 & 1 & 7 & 8 \\
\hline 2 & 10 & 8 & 18 & 14 & 6 & 20 \\
\hline 3 & 48 & 35 & 83 & 54 & 40 & 94 \\
\hline Diabetes insipidus & 22 & 15 & 37 & 23 & 18 & 41 \\
\hline
\end{tabular}


and safety monitoring were performed every third month during the first year and every sixth month thereafter. Body weight was measured in the morning to the nearest $0.1 \mathrm{~kg}$ and body height was measured to the nearest $0.01 \mathrm{~m}$. Body mass index (BMI) was calculated as the weight in kilograms divided by the height in meters squared. No effort was made to influence the patients' physical activity level during the study period.

\section{Ethical considerations}

Informed consent was obtained from all patients. The study was approved by the Regional Ethics Review Board at the University of Gothenburg and the Swedish Medical Products Agency (Uppsala, Sweden).

\section{BMC and BMD}

BMC and BMD were measured by dual-energy X-ray absorptiometry (DXA) in the total body, lumbar spine and femur neck as described previously (23). From the initiation of the study until the end of 1999, a LUNAR DPX-L scanner was used (Scanex, Helsingborg, Sweden). Software versions were changed several times (from 1.1 to 1.35 ), version 1.33 being used during the major part of this period of the study. In-house precision error on the scanner used, as determined from duplicate examinations in ten healthy subjects, was $1.9 \%$ for total body BMC. From January 2000, a LUNAR Prodigy scanner (Scanex) was used. Software versions were upgraded several times during data collection, from version 5.70 to 8.10 . The precision of the scanner was estimated from repeated measurements on different days in 30 subjects with coefficients of variation $(\mathrm{CV})$ of total body BMC of $1.4 \%$. Before the change of scanner in 2000, 31 subjects (19 males and 12 females), ranging in weight from 51 to $112 \mathrm{~kg}$, were scanned on both scanners on the same day. Total body BMD was not significantly different between scanners (mean difference, $0.019 \mathrm{~g} / \mathrm{cm}^{2} ; 95 \%$ confidence interval for the difference, -0.0079 to $0.00458 \mathrm{~g} / \mathrm{cm}^{2}$ ).

Daily quality control was performed according to the manufacturer's protocol. A spine phantom was measured at least once a week. Every single spine phantom measurement was compared with a baseline value based on a mean of ten repeated measurements. A maximum $1.5 \%$ deviation from the baseline value was accepted. A European phantom (COMAC-BME Quantitative Assessment of Osteoporosis Study Group) was measured once a year. BMD $z$-score, which is the difference in S.D. of age- and sex-matched healthy subjects, and $t$-score, which is the difference in s.D. of sex-matched young (20-39 years) healthy subjects, were determined using the Lunar DPX-L Software program. The reference database used was the LUNAR USA reference population for the region examined.

\section{Biochemical analysis}

Serum IGF1 concentration, until June 2004, was determined using a hydrochloric acid-ethanol extraction RIA (Nichols Institute Diagnostics, San Juan Capistrano, CA, USA). Inter- and intra-assay CV were 5.4 and $6.9 \%$ respectively, at a mean serum IGF1 level of $126 \mu \mathrm{g} / \mathrm{l}$, and 4.6 and $4.7 \%$ respectively, at a mean serum IGF1 level of $327 \mu \mathrm{g} / \mathrm{l}$. From June 2004 to August 2006, serum IGF1 concentration was determined using a chemiluminescence immunoassay (Nichols Advantage; Nichols Institute Diagnostics) (24). From September 2006, serum IGF1 level was determined using an automated chemiluminescent assay system (IMMULITE 2500, Diagnostic Products Corp., Los Angeles, CA, USA). The standard used for calibration of the IGF1 assays was the WHO NIBSC 1st IRR $87 / 518$ throughout the study period. The individual serum IGF1 values were compared with age- and sex-adjusted values obtained from a reference population (25), and the individual IGF1 SDSs, taking into account age and gender, were then calculated (26).

\section{Statistical methods}

All the descriptive statistical results are presented as the mean and S.E.M. For all variables, within-group differences were calculated using a repeated measures ANOVA, with all data obtained from all time points, and with time as the independent variable. Post hoc analysis was performed using Student-Newman-Keuls test. Gender differences and differences between women on oestrogen replacement and women without oestrogen replacement were calculated by a two-way ANOVA, with all data obtained from all time points, and with gender or oestrogen treatment as the independent variables. In order to eliminate the baseline differences, data were transformed into percent change or change from baseline before the between-group analyses. All analyses were performed according to the intention-to-treat principle (using the carry forward principle). A two-tailed $P<0.05$ was considered significant.

\section{Results}

\section{GH dose and serum IGF1}

The dose of $\mathrm{GH}$ prescribed at the baseline visit was 0.63 (0.03) mg/day (Table 3). The dose was then gradually reduced to $0.41(0.01) \mathrm{mg} /$ day at study end. Serum IGF1 levels increased during the first years of the study and then decreased to some extent. Mean IGF1 SDS (adjustment for age and gender) was above the normal range during the first 3 years of the study, but after that, it was within the normal range ( \pm 2 S.D.). 
Table 3 The dose of GH during 15 years of GH replacement in $126 \mathrm{GH}$-deficient adults and the effects of this treatment on serum IGF1 concentration and IGF1 SDS. All values are shown as the mean (S.E.M.). The statistical analyses are based on a one-way ANOVA followed by Student-Newman-Keuls post hoc test.

\begin{tabular}{|c|c|c|c|c|c|c|c|c|}
\hline & Baseline & 3 years & 5 years & 7 years & 10 years & 12 years & 15 years & $\begin{array}{c}\boldsymbol{P} \text { value } \\
\text { (10-15 years) }\end{array}$ \\
\hline $\begin{array}{l}\text { Dose of GH }(\mathrm{mg} / \mathrm{day}) \\
\text { Serum IGF1 }(\mu \mathrm{g} / \mathrm{l}) \\
\text { IGF1 SDS }\end{array}$ & $\begin{array}{c}0.63(0.03) \\
103(6) \\
-1.69(0.11)\end{array}$ & $\begin{array}{l}0.51(0.02)^{\ddagger} \\
298(10)^{\ddagger} \\
2.28(0.21)^{\ddagger}\end{array}$ & $\begin{array}{l}0.49(0.02)^{\ddagger} \\
273(10)^{\ddagger} \\
1.89(0.21)^{\ddagger}\end{array}$ & $\begin{array}{l}0.46(0.02)^{\ddagger} \\
246(8)^{\ddagger} \\
1.47(0.18)^{\ddagger}\end{array}$ & $\begin{array}{l}0.44(0.02)^{\ddagger} \\
206(8)^{\ddagger} \\
0.84(0.17)^{\ddagger}\end{array}$ & $\begin{array}{l}0.42(0.02)^{\ddagger} \\
188(7)^{\ddagger} \\
0.56(0.16)^{\ddagger}\end{array}$ & $\begin{array}{l}0.41(0.01)^{\ddagger} \\
183(7)^{\ddagger} \\
0.62(0.16)^{\ddagger}\end{array}$ & $\begin{array}{l}<0.001 \\
<0.001 \\
<0.05\end{array}$ \\
\hline
\end{tabular}

$P$ values (10-15 years) are based on the statistical analysis between the 10 - and 15-year values. NS, non-significant. ${ }^{\ddagger} P<0.001$ (for the dose of GH vs initial $\mathrm{GH}$ dose; for other variables vs baseline).

\section{Height, weight and BMI}

Mean body height decreased from $171.8(0.94) \mathrm{cm}$ at baseline to $171.3(0.97) \mathrm{cm}$ after 15 years $(P<0.001$; data not shown). Mean body weight increased from 81.5 (1.5) to $83.7(1.5) \mathrm{kg}(P<0.001)$ and BMI increased from $27.6(0.44) \mathrm{kg} / \mathrm{m}^{2}$ at baseline to 28.5 $(0.44) \mathrm{kg} / \mathrm{m}^{2}$ at the end of the study $(P<0.001)$.

\section{BMC and BMD}

GH replacement gradually increased total body BMC during the first 5 years of treatment as measured using DXA (Table 4). Thereafter, total body BMC increased slowly throughout the study period. After 15 years, mean total body BMC was 5\% above the baseline value $(P<0.001)$. Total body BMD had increased by $2 \%$ after 10 years $(P<0.001$ vs baseline $)$ and then reached a plateau. Total body $t$-score, after an initial decrease, increased up to 10 years and then stayed at a constant level. Total body $z$-score tended to decrease during the first 5 years of treatment and then increased during the remaining part of the study.

Lumbar (L2-L4) spine BMC increased throughout the study period and was $9 \%$ above the baseline value after 15 years of GH replacement $(P<0.001$ vs baseline; Table 4$)$. Lumbar (L2-L4) spine BMD and $t$-score increased up to 10 years of GH treatment and remained at a constant level between 10 and 15 years. After 15 years, lumbar (L2-L4) spine BMD was 5\% above the baseline value $(P<0.001$ vs baseline). Lumbar (L2-L4) spine $z$-score increased progressively throughout the study period.

Femur neck BMC reached a maximum level of $7 \%$ above baseline $(P<0.001)$ after 7 years (Table 4$)$. After that, femur neck BMC decreased and was $5 \%$ above the baseline value after 15 years $(P<0.01)$. Femur neck BMD increased to a maximum level of $3 \%$ above baseline after 7 years of treatment $(P<0.001)$. Femur neck BMD then decreased and returned to the baseline level after 15 years. Femur neck $z$-score reached a maximum after 7 years and then decreased but remained significantly elevated over the baseline level after 15 years.

Table 4 Effects of 15 years of GH replacement in 126 adults with GH deficiency on BMC, BMD, $z$-score and $t$-score as measured using DXA. All values are shown as the mean (S.E.M.). The statistical analyses are based on a repeated measures ANOVA followed by StudentNewman-Keuls post hoc test.

\begin{tabular}{|c|c|c|c|c|c|c|c|c|}
\hline & $\begin{array}{l}\text { Baseline } \\
(n=126)\end{array}$ & $\begin{array}{c}3 \text { years } \\
(n=120)\end{array}$ & $\begin{array}{l}5 \text { years } \\
(n=112)\end{array}$ & $\begin{array}{l}7 \text { years } \\
(n=111)\end{array}$ & $\begin{array}{l}10 \text { years } \\
(n=103)\end{array}$ & $\begin{array}{c}12 \text { years } \\
(n=98)\end{array}$ & $\begin{array}{c}15 \text { years } \\
(n=90)\end{array}$ & $\begin{array}{c}\boldsymbol{P} \text { value } \\
(10-15 \text { years })\end{array}$ \\
\hline \multicolumn{9}{|l|}{ DXA total body } \\
\hline $\mathrm{BMC}(\mathrm{kg})$ & $2.73(0.06)$ & $2.77(0.06)$ & $2.81(0.06)^{\star}$ & $2.83(0.06)^{\dagger}$ & $2.83(0.07)^{\ddagger}$ & $2.83(0.07)^{\ddagger}$ & $2.87(0.07)^{\ddagger}$ & NS \\
\hline $\operatorname{BMD}\left(\mathrm{g} / \mathrm{cm}^{2}\right)$ & $1.17(0.01)$ & $1.16(0.01)$ & $1.16(0.01)$ & $1.17(0.01)$ & $1.19(0.01)^{\dagger}$ & $1.19(0.02)^{\ddagger}$ & $1.19(0.02)^{\ddagger}$ & NS \\
\hline$t$-Score (S.D.) & $-0.05(0.13)$ & $-0.19(0.14)$ & $-0.18(0.14)^{*}$ & $0.04(0.15)$ & $0.19(0.16)^{\dagger}$ & $0.22(0.17)^{\ddagger}$ & $0.19(0.17)^{\dagger}$ & NS \\
\hline$z$-Score (S.D.) & $-0.11(0.11)$ & $-0.20(0.10)$ & $-0.19(0.11)$ & $0.06(0.11)^{\star}$ & $0.36(0.13)^{\ddagger}$ & $0.43(0.14)^{\ddagger}$ & $0.42(0.13)^{\ddagger}$ & NS \\
\hline \multicolumn{9}{|c|}{ DXA lumbar (L2-L4) spine } \\
\hline $\mathrm{BMC}(\mathrm{g})$ & $55.5(1.5)$ & $58.1(1.7)^{\ddagger}$ & $59.1(1.8)^{\ddagger}$ & $59.5(1.8)^{\ddagger}$ & $60.3(1.9)^{\ddagger}$ & $60.3(1.9)^{\ddagger}$ & $60.7(2.0)^{\ddagger}$ & NS \\
\hline $\operatorname{BMD}\left(\mathrm{g} / \mathrm{cm}^{2}\right)$ & $1.17(0.02)$ & $1.20(0.02)^{\ddagger}$ & $1.22(0.02)^{\ddagger}$ & $1.22(0.02)^{\ddagger}$ & $1.24(0.02)^{\ddagger}$ & $1.23(0.02)^{\ddagger}$ & $1.23(0.02)^{\ddagger}$ & NS \\
\hline$t$-Score (S.D.) & $-0.44(0.15)$ & $-0.13(0.17)^{\ddagger}$ & $0.03(0.18)^{\ddagger}$ & $0.06(0.18)^{\ddagger}$ & $0.19(0.20)^{\ddagger}$ & $0.13(0.20)^{\ddagger}$ & $0.18(0.21)^{\ddagger}$ & NS \\
\hline z-Score (S.D.) & $-0.01(0.14)$ & $0.19(0.14)$ & $0.35(0.15)^{\ddagger}$ & $0.39(0.16)^{\ddagger}$ & $0.63(0.18)^{\ddagger}$ & $0.62(0.18)^{\ddagger}$ & $0.77(0.19)^{\ddagger}$ & 0.01 \\
\hline \multicolumn{9}{|c|}{ DXA femur neck } \\
\hline $\mathrm{BMC}(\mathrm{g})$ & $4.87(0.14)$ & $5.04(0.14)$ & $5.14(0.12)^{\dagger}$ & $5.20(0.12)^{\ddagger}$ & $5.15(0.12)^{\dagger}$ & $5.13(0.13)^{\dagger}$ & $5.12(0.13)^{\dagger}$ & NS \\
\hline $\operatorname{BMD}\left(\mathrm{g} / \mathrm{cm}^{2}\right)$ & $0.94(0.01)$ & $0.96(0.01)^{\star}$ & $0.96(0.02)^{\dagger}$ & $0.97(0.02)^{\ddagger}$ & $0.96(0.02)$ & $0.95(0.02)$ & $0.94(0.02)$ & $<0.001$ \\
\hline$t$-Score (S.D.) & $-0.71(0.12)$ & $-0.45(0.14)^{\dagger}$ & $-0.49(0.11)^{*}$ & $-0.45(0.12)^{\dagger}$ & $-0.52(0.12)^{*}$ & $-0.63(0.12)$ & $-0.75(0.12)$ & $<0.001$ \\
\hline$z$-Score (S.D.) & $-0.23(0.10)$ & $0.10(0.12)^{\ddagger}$ & $0.17(0.10)^{\ddagger}$ & $0.24(0.10)^{\ddagger}$ & $0.24(0.10)^{\ddagger}$ & $0.18(0.11)^{\ddagger}$ & $0.15(0.11)^{\ddagger}$ & $<0.05$ \\
\hline
\end{tabular}

$P$ values (10-15 years) are based on the statistical analysis between the 10 - and 15 -year values. NS, non-significant; $n$, number of patients on GH replacement at different time points; however, all 126 patients were included in the statistical analysis according to the intention-to-treat approach used. A separate analysis of the patients $(n=90)$ who completed the 15 years of $\mathrm{GH}$ replacement showed approximately similar results (data not shown). ${ }^{\star} P<0.05 ;{ }^{\dagger} P<0.01 ;{ }^{\ddagger} P<0.001$ vs baseline. 
A

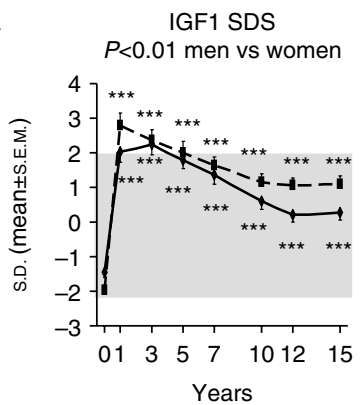

C

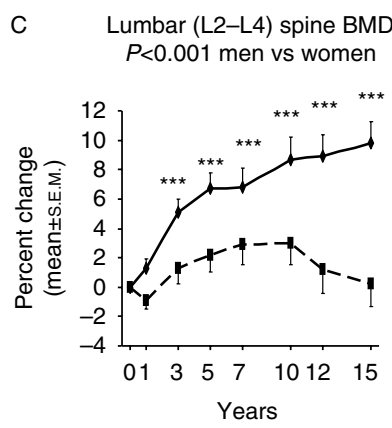

Lumbar (L2-L4) spine BMD D
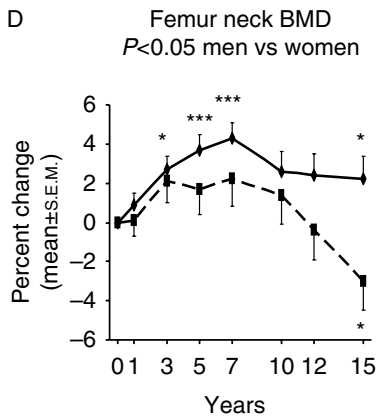

$\longrightarrow$ Men - +-. Women

Figure 1 The gender differences in the effects of 15 years of $\mathrm{GH}$ replacement in $126 \mathrm{GH}$-deficient adults on IGF1 SDS (A) and BMD in total body (B), lumbar (L2-L4) spine (C) and femur neck (D). IGF1 SDS are shown as S.D. for men and women. The grey rectangle shows the normal range of -2 to +2 s.D. The results in BMD are shown as percent change from baseline. The vertical bars indicate the S.E.M. values shown. $P$ values for men vs women are based on a two-way ANOVA of the percent change from baseline in each group. ${ }^{\star} P<0.05 ;{ }^{\star \star \star} P<0.001$ vs baseline.

\section{Gender differences}

Except for the initial dose of $\mathrm{GH}$, women received a higher dose of GH than men $(P<0.001)$. The mean initial GH dose was $0.71(0.04) \mathrm{mg} /$ day for men and $0.53(0.04) \mathrm{mg} /$ day for women whereas at study end, the mean GH dose was $0.38(0.02) \mathrm{mg} /$ day for men and $0.45(0.03) \mathrm{mg} /$ day for women $(P<0.05)$. IGF1 SDS increased from $-1.46(0.14)$ at baseline to 0.27 after 15 years of $\mathrm{GH}$ replacement in men and from -1.98 $(0.16)$ to $1.10(0.22)$ in women $(P<0.01$ men vs women; Fig. 1). Men had, however, a greater increase than women in BMD at all skeletal locations measured (Fig. 1). Similar gender differences, with men being more responsive, were seen for BMC, $t$-scores and $z$-scores except for femur neck BMC, where there was no significant gender difference (data not shown).

\section{Women on oestrogen replacement vs women without oestrogen replacement}

Forty-eight of the 54 included women were gonadotrophin deficient. Twenty-five (52\%) women at the initiation of the study and $15(31 \%)$ at the study end received oestrogen replacement therapy. The reason for fewer women receiving oestrogen replacement at study end compared with baseline was discontinuation because of age. The women receiving oestrogen replacement at baseline were significantly younger (mean age 44.5 (2.1) years) than the women without oestrogen therapy (mean age 57.5 (2.2) years, $P<0.001)$. Women on oestrogen replacement therapy received a significantly higher dose of $\mathrm{GH}$ than women without oestrogen replacement $(P<0.001)$. There was no difference in serum IGF1 level or IGF1 SDS between women with and without oestrogen replacement. There was also no difference in treatment response in BMD or BMC at any skeletal site measured.

\section{Osteopenia and osteoporosis}

At baseline, 37.8 and $38.8 \%$ of the patients had osteopenia $(t$-score $<-1.0$ s.D.) in the lumbar (L2-L4) spine and femur neck respectively (Table 5). After 15 years of $\mathrm{GH}$ replacement, $30.6 \%$ of the patients had osteopenia in the lumbar (L2-L4) spine and $40.8 \%$ in the femur neck (Table 5). The patients with remaining osteopenia at study end, as measured in the femur neck, were older (mean age 67.6 (1.7) vs 62.4 (1.5) years respectively, $P<0.05)$ and included a larger proportion of women (61.1 vs $38.7 \%$ respectively). Among the patients with osteopenia in the lumbar (L2-L4) spine after 15 years of GH replacement, $69.0 \%$ were women compared with $37.7 \%$ women among patients without osteopenia, but there was no age difference.

Table 5 Osteopenia ( $t$-score $<-1.0$ s.D.) and osteoporosis ( $t$-score $<-2.5$ s.D.) at baseline and after 15 years of GH replacement therapy in $126 \mathrm{GH}$-deficient adults. Patients with an increase in $t$-score of $>0.5$ were arbitrarily considered to have an increase in $t$-score. Likewise, patients with a decrease in $t$-score of $>0.5$ were considered to have a decrease in $t$-score and patients with an increase or decrease in $t$-score of $<0.5$ were considered to have an unchanged $t$-score.

\begin{tabular}{|c|c|c|c|c|c|c|c|}
\hline & \multicolumn{2}{|c|}{ Baseline (\%) } & \multicolumn{5}{|c|}{ After 15 years $(\%)$} \\
\hline & $\begin{array}{l}\text { Osteopenia } \\
\quad(t \text {-score } \\
<-1.0 \text { s.D. })\end{array}$ & $\begin{array}{c}\text { Osteoporosis } \\
\text { (t-score } \\
<-2.5 \text { s.D. })\end{array}$ & Increased & Unchanged & Decreased & $\begin{array}{l}\text { Osteopenia } \\
\quad(t \text {-score } \\
<-1.0 \text { S.D. })\end{array}$ & $\begin{array}{l}\text { Osteoporosis } \\
\quad(t \text {-score } \\
<-2.5 \text { s.D. })\end{array}$ \\
\hline $\begin{array}{l}\text { Total body } \\
\text { Lumbar (L2-L4) } \\
\text { spine }\end{array}$ & $\begin{array}{l}23.5 \\
37.8\end{array}$ & $\begin{array}{l}5.1 \\
9.2\end{array}$ & $\begin{array}{l}43.9 \\
50.0\end{array}$ & $\begin{array}{l}33.7 \\
34.7\end{array}$ & $\begin{array}{l}22.4 \\
15.3\end{array}$ & $\begin{array}{l}24.5 \\
30.6\end{array}$ & $\begin{array}{r}6.1 \\
11.2\end{array}$ \\
\hline Femur neck & 38.8 & 7.1 & 24.5 & 46.9 & 28.6 & 40.8 & 7.1 \\
\hline
\end{tabular}



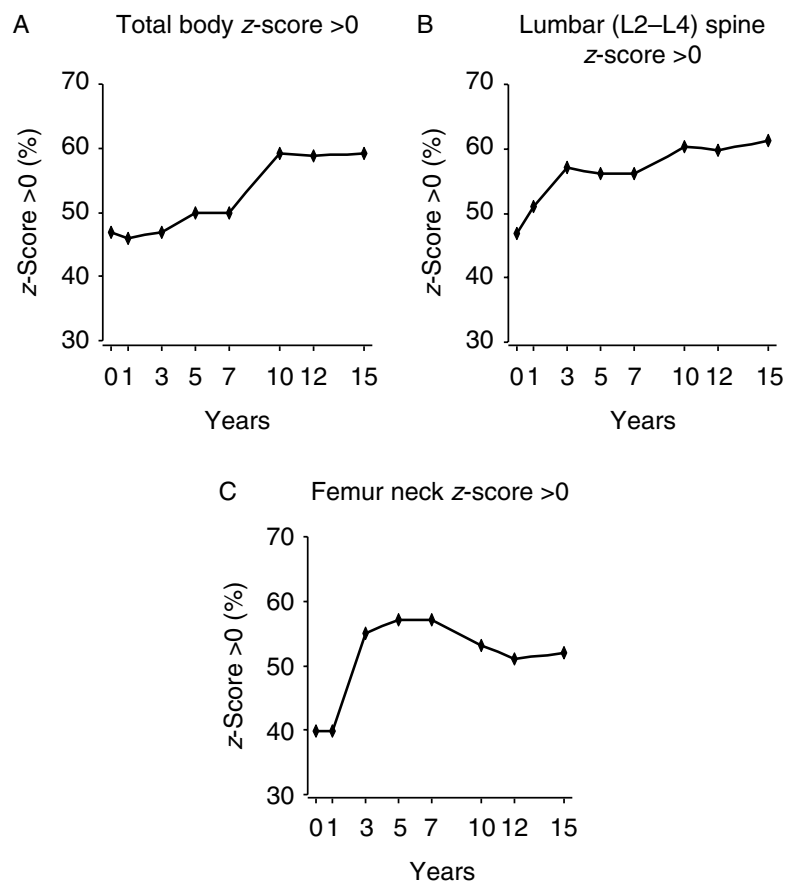

Figure 2 The percentage of patients with normal BMD adjusted for age, i.e. $z$-score $>0$, in total body (A), lumbar (L2-L4) spine (B) and femur neck $(\mathrm{C})$ during 15 years of $\mathrm{GH}$ replacement to 126 adults with GH deficiency. In all locations, the percentage of patients with $z$-score $>0$ increased throughout the study period.

An analysis of the percentage of patients who responded to the 15 years of $\mathrm{GH}$ replacement in terms of $t$-scores is summarised in Table 5. Furthermore, the percentage of patients with normal BMD corrected for age and gender $(z$-score $>0)$ are shown in Fig. 2 .

\section{Fractures}

No fractures were reported in men. One woman suffered from a hip fracture and one woman had a symptomatic vertebral fracture, both after 7 years of GH replacement. X-ray examinations were not performed to determine asymptomatic vertebral fractures. No patient had a height loss of $>5 \mathrm{~cm}$ whereas two men and four women had a height loss of $3-4.5 \mathrm{~cm}$.

\section{Correlation}

Baseline femur neck BMC correlated inversely with the percent change in the same variable $(r=-0.47$, $P<0.001)$. This indicates that those patients with the lowest femur neck BMC at baseline had the greatest increase in this variable after 15 years of $\mathrm{GH}$ replacement. There was no correlation between the baseline value and the percent change in any other variable reflecting bone mass and density.

At baseline, there were positive correlations between serum IGF1 and total body BMC $(r=0.31, P<0.01)$ and BMD $(r=0.35, P<0.001)$, lumbar (L2-L4) spine BMC $(r=0.24, P<0.05)$ and BMD $(r=0.26, P<0.01)$, and femur neck BMC $(r=0.26, P=0.01)$ and BMD $(r=0.30, P<0.01)$.

The percent change in serum IGF1 correlated positively with the percent change in femur neck BMC ( $r=0.25, P=0.01)$, indicating that those patients with the highest increase in serum IGF1 had the greatest treatment response in terms of femur neck BMC. No correlation was seen at study end between the percent change in serum IGF1 and the percent change in BMC or BMD at other skeletal sites.

There was no correlation between the $\mathrm{GH}$ dose at study end and the percent change in any of the DXA variables measured.

\section{Discussion}

This single-centre study is the longest and one of the largest studies of the effects of GH replacement therapy in patients with AO GHD on bone mass and density. The results show that 15 years of $\mathrm{GH}$ replacement induced a sustained increase in total body and lumbar (L2-L4) spine BMC and BMD. At study end, all z-scores were normalised (above zero).

Total body and lumbar (L2-L4) spine BMC, BMD, $t$-score and $z$-score values were significantly above the baseline levels after 15 years of $\mathrm{GH}$ replacement. The main increase occurred during the first 7-10 years. The results of previous studies suggest, taken together, that $\mathrm{GH}$ replacement increases BMC and BMD during the first 5-10 years of therapy, whereas after that a plateau is reached in the absolute values of BMC and $\operatorname{BMD}(13,15,19,20,22)$. There are no previous studies over a longer period than 10 years. In this study, no further gain in absolute values of total body and lumbar (L2-L4) spine BMC and BMD occurred between 10 and 15 years of GH replacement. However, lumbar (L2-L4) spine $z$-score was increased at 15 years compared with the 10-year value. In the femur neck, the response to 15 years of $\mathrm{GH}$ replacement was different compared with the responses in total body and lumbar (L2-L4) spine. Femur neck BMC and BMD increased to a maximum after 7 years and then started to decrease. After 15 years, femur neck BMD and $t$-score had returned to the baseline value.

The reason why bone mass and density decreased between 10 and 15 years of GH replacement in the femur neck and not in the lumbar spine is not fully clear. Femur neck is composed of more cortical bone whereas lumbar spine is composed of more trabecular bone (27). It is well known that the trabecular bone in the lumbar spine is sensitive to sex steroids, which is noticed for instance in postmenopausal women (27). In the femur neck, with predominantly cortical bone, BMD decreases with increasing age resulting in senile osteoporosis, which affects both elderly men and women (27). It is 
therefore possible that the sex steroid replacement used in this study contributed to the increase in bone density at lumbar (L2-L4) spine whereas it had only a lesser effect on bone mass in femur neck. Furthermore, the dose of GH was gradually reduced during the study period and the possibility cannot be excluded that the dose of GH used at study end was not sufficiently high to maintain the increase in femur neck bone mass and density. In some support of this assumption, the percent change in serum IGF1 correlated positively with the percent change in femur neck BMC after 15 years, indicating that the patients with the highest increase in serum IGF1, and therefore likely the highest dose of $\mathrm{GH}$, had the greatest treatment response in terms of femur neck BMC.

In all variables at all skeletal sites, except for femur neck BMC, men had a greater treatment response to GH replacement than women. Similar gender differences in responsiveness have been observed in several previous studies $(13,15,16,18,19)$. The mechanisms underlying these gender differences are not fully understood, but sex hormones might play a role (19). In terms of oestrogens, there was no difference in the treatment responses in BMD or BMC at any skeletal site measured between gonadotrophin-deficient women receiving or not receiving oestrogen replacement at baseline. However, a smaller number of women received oestrogen replacement at study end $(n=15)$ than at baseline $(n=25)$, which could have contributed to the lack of difference between women with and without oestrogen therapy. Further studies are therefore needed to clarify the importance of oestrogen replacement during long-term GH replacement. Moreover, androgens may interact with GH, resulting in increased bone mass (19). The possibility cannot be excluded that the testosterone replacement contributed to increased bone mass and density in the GHD men, although this could not be evaluated in more detail as most men were gonadotrophin deficient and all gonadotrophin-deficient men received testosterone replacement.

A main question is whether $\mathrm{GH}$ replacement reduces the risk of fractures. Patients with GHD that do not receive GH replacement have an increased risk of fractures $(8,9,10)$. There are some indications that GH replacement can reduce the incidence of fractures $(10,28)$. Although increased number of falls due to visual impairment caused by pituitary tumours or their treatment could be of importance, BMD $t$-score has been shown as an important predictor of fracture risk (29, 30). Therefore, an increase in bone mass and density, and especially BMD $t$-score, probably means that 15 years of GH replacement can reduce the fracture risk in GHD patients. Two fractures were reported in this study: one hip fracture and one symptomatic vertebral fracture. X-ray examinations were not performed to determine asymptomatic vertebral fractures. However, it has been estimated that two-thirds to three-quarters of vertebral fractures are asymptomatic and therefore remain undiagnosed (31). Patients with vertebral fractures have a mean height loss of around $5 \mathrm{~cm} \mathrm{(32,}$ 33). No patient in our study had a height loss of $5 \mathrm{~cm}$ or more whereas six patients (two men) had a height loss of $3-4.5 \mathrm{~cm}$. Therefore, we cannot exclude the possibility that a few of the GHD patients included in this study had asymptomatic vertebral fractures. Furthermore, this study is too small to evaluate fracture incidence. This would need large, probably multi-centre studies because GHD is a relatively rare condition and most centres do not have enough patients to evaluate the risk of fractures.

A limitation of the study is the lack of a control group. For ethical reasons, the study cannot be made with a control group of GHD patients without $\mathrm{GH}$ replacement. The use of $t$-scores and $z$-scores may to some extent compensate for the lack of a longitudinal control group. At the end of 1999, the DXA machine used was changed. The new DXA was, however, calibrated to show as similar values as possible compared with the old DXA. In terms of $t$-scores and $z$-scores, the LUNAR USA reference population was used as the reference database throughout the study period. Furthermore, the level of physical activity was not recorded. However, no effort was made to influence the patients' physical activity level during the study period. Another limitation of the study is that the IGF1 assay was changed two times. Although the WHO NIBSC 1st IRR 87/518 standard was used for calibration throughout the study period, it cannot be excluded that the changes in IGF1 assay could have influenced the results of the IGF1 measurements. Finally, all patients were retained in the statistical analysis according to the intentionto-treat principle used. A separate analysis of the patients $(n=90)$ who completed the 15 years of GH replacement was made and showed similar results (data not shown).

In conclusion, this study shows that 15 years of GH replacement to GHD adults induces a sustained increase in total body and lumbar (L2-L4) spine BMD and BMC. Femur neck BMC and BMD peaked after 7 years of treatment and then decreased towards baseline values, which might be due to the mean GH dose being relatively low during the last years of the study. Our study is the first that has studied the effect of 15 years of GH replacement and the results give further support to the usefulness of long-term GH replacement to GHD adults. It remains to be investigated in studies larger than the present one whether 15 years of GH replacement reduce the risk of fractures. Men had a greater treatment response than women despite women receiving a higher dose of GH. Further studies that look in more detail into the effect of sex hormones are needed to clarify the mechanisms behind these gender differences. 


\section{Declaration of interest}

G Johannsson has received lecture fees from Pfizer, Novo Nordisk, Merck Serono and Eli Lilly and is a member of the SAB for KIMS Pfizer. B- $\AA$ Bengtsson has previously received a research grant from Pharmacia/Pfizer. None of the other authors has any conflict of interest.

\section{Funding}

This study was supported by the Swedish Research Council, the Sahlgrenska Academy at the University of Gothenburg and Novo Nordisk.

\section{Acknowledgements}

We are indebted to Lena Wirén, Ingrid Hansson, Annika Alklind, Ann-Charlotte Olofsson, Annika Reibring and Anna Olsson at the Research Centre for Endocrinology and Metabolism for their skilful technical support.

\section{References}

1 Rosen T, Hansson T, Granhed H, Szucs J \& Bengtsson BA. Reduced bone mineral content in adult patients with growth hormone deficiency. Acta Endocrinologica 1993129 201-206.

2 Ohlsson C, Bengtsson BA. Isaksson OG, Andreassen TT \& Slootweg MC. Growth hormone and bone. Endocrine Reviews 199819 55-79. (doi:10.1210/er.19.1.55)

3 Molitch ME, Clemmons DR, Malozowski S, Merriam GR \& Vance ML. Evaluation and treatment of adult growth hormone deficiency: an Endocrine Society clinical practice guideline. Journal of Clinical Endocrinology and Metabolism 2011 96 1587-1609. (doi:10.1210/jc.2011-0179)

4 Tritos NA \& Biller BM. Growth hormone and bone. Current Opinion in Endocrinology, Diabetes, and Obesity 200916 415-422. (doi:10.1097/MED.0b013e3283319e6d)

5 Koranyi J, Svensson J, Gotherstrom G, Sunnerhagen KS, Bengtsson B \& Johannsson G. Baseline characteristics and the effects of five years of $\mathrm{GH}$ replacement therapy in adults with $\mathrm{GH}$ deficiency of childhood or adulthood onset: a comparative, prospective study. Journal of Clinical Endocrinology and Metabolism 200186 4693-4699. (doi:10.1210/jc.86.10.4693)

6 Fernholm R, Bramnert M, Hagg E, Hilding A, Baylink DJ, Mohan S \& Thoren M. Growth hormone replacement therapy improves body composition and increases bone metabolism in elderly patients with pituitary disease. Journal of Clinical Endocrinology and Metabolism $2000 \mathbf{8 5}$ 4104-4112. (doi:10. 1210/jc.85.11.4104)

7 Toogood AA, Adams JE, O'Neill PA \& Shalet SM. Elderly patients with adult-onset growth hormone deficiency are not osteopenic. Journal of Clinical Endocrinology and Metabolism $1997 \mathbf{8 2} 1462-1466$. (doi:10.1210/jc.82.5.1462)

8 Rosen T, Wilhelmsen L, Landin-Wilhelmsen K, Lappas G \& Bengtsson BA. Increased fracture frequency in adult patients with hypopituitarism and $\mathrm{GH}$ deficiency. European Journal of Endocrinology 1997137 240-245. (doi:10.1530/eje.0.1370240)

9 Wuster C. Fracture rates in patients with growth hormone deficiency. Hormone Research 200054 (Suppl 1) 31-35. (doi:10. 1159/000053295)

10 Wuster C, Abs R, Bengtsson BA, Bennmarker H, FeldtRasmussen U, Hernberg-Stahl E, Monson JP, Westberg B \& Wilton P. The influence of growth hormone deficiency, growth hormone replacement therapy, and other aspects of hypopituitarism on fracture rate and bone mineral density. Journal of Bone and Mineral Research 2001 16 398-405. (doi:10.1359/jbmr.2001.16. 2.398)
11 Ueland T, Odgren PR, Yndestad A, Godang K, Schreiner T, Marks SC \& Bollerslev J. Growth hormone substitution increases gene expression of members of the IGF family in cortical bone from women with adult onset growth hormone deficiency - relationship with bone turn-over. Bone 200333 638-645. (doi:10.1016/ S8756-3282(03)00240-0)

12 Klefter $\mathrm{O} \&$ Feldt-Rasmussen U. Is increase in bone mineral content caused by increase in skeletal muscle mass/strength in adult patients with GH-treated GH deficiency? A systematic literature analysis European Journal of Endocrinology $2009161213-221$. (doi:10.1530/EJE-09-0160)

13 Biermasz NR, Hamdy NA, Pereira AM, Romijn JA \& Roelfsema F. Long-term skeletal effects of recombinant human growth hormone $(\mathrm{rhGH})$ alone and rhGH combined with alendronate in GH-deficient adults: a seven-year follow-up study. Clinical Endocrinology 200460 568-575. (doi:10.1111/j.1365-2265. 2004.02021.x)

14 Drake WM, Howell SJ, Monson JP \& Shalet SM. Optimizing GH therapy in adults and children. Endocrine Reviews 200122 425-450. (doi:10.1210/er.22.4.425)

15 Gotherstrom G, Svensson J, Koranyi J, Alpsten M, Bosaeus I, Bengtsson B \& Johannsson G. A prospective study of 5 years of GH replacement therapy in $\mathrm{GH}$-deficient adults: sustained effects on body composition, bone mass, and metabolic indices. Journal of Clinical Endocrinology and Metabolism 200186 4657-4665. (doi:10.1210/jc.86.10.4657)

16 Johansson AG, Engstrom BE, Ljunghall S, Karlsson FA \& Burman P. Gender differences in the effects of long term growth hormone $(\mathrm{GH})$ treatment on bone in adults with $\mathrm{GH}$ deficiency. Journal of Clinical Endocrinology and Metabolism 1999842002 2007. (doi:10.1210/jc.84.6.2002)

17 Bex M, Abs R, Maiter D, Beckers A, Lamberigts G \& Bouillon R. The effects of growth hormone replacement therapy on bone metabolism in adult-onset growth hormone deficiency: a 2-year open randomized controlled multicenter trial. Journal of Bone and Mineral Research 200217 1081-1094. (doi:10.1359/jbmr.2002. 17.6.1081)

18 Rossini A, Lanzi R, Losa M, Sirtori M, Gatti E, Madaschi S, Molinari C, Villa I, Scavini M \& Rubinacci A. Predictors of bone responsiveness to growth hormone $(\mathrm{GH})$ replacement in adult GH-deficient patients. Calcified Tissue International 201188304 313. (doi:10.1007/s00223-010-9459-8)

19 Drake WM, Rodriguez-Arnao J, Weaver JU, James IT, Coyte D, Spector TD, Besser GM \& Monson JP. The influence of gender on the short and long-term effects of growth hormone replacement on bone metabolism and bone mineral density in hypopituitary adults: a 5-year study. Clinical Endocrinology 2001 54 525-532. (doi:10.1046/j.1365-2265.2001.01246.x)

20 Clanget C, Seck T, Hinke V, Wuster C, Ziegler R \& Pfeilschifter J. Effects of 6 years of growth hormone $(\mathrm{GH})$ treatment on bone mineral density in GH-deficient adults. Clinical Endocrinology 2001 55 93-99. (doi:10.1046/j.1365-2265.2001.01284.x)

21 Jorgensen AP, Fougner KJ, Ueland T, Gudmundsen O, Burman P, Schreiner T \& Bollerslev J. Favorable long-term effects of growth hormone replacement therapy on quality of life, bone metabolism, body composition and lipid levels in patients with adult-onset growth hormone deficiency. Growth Hormone \& IGF Research 2011 21 69-75. (doi:10.1016/j.ghir.2011.01.001)

22 Gotherstrom G, Bengtsson BA, Bosaeus I, Johannsson G \& Svensson J. Ten-year GH replacement increases bone mineral density in hypopituitary patients with adult onset GH deficiency. European Journal of Endocrinology 2007156 55-64. (doi:10.1530/ eje.1.02317)

23 Mazess RB, Barden HS, Bisek JP \& Hanson J. Dual-energy X-ray absorptiometry for total-body and regional bone-mineral and soft-tissue composition. American Journal of Clinical Nutrition 1990 51 1106-1112.

24 Brabant G, von zur Muhlen A, Wuster C, Ranke MB, Kratzsch J, Kiess W, Ketelslegers JM, Wilhelmsen L, Hulthen L, Saller B, Mattsson A, Wilde J, Schemer R \& Kann P. Serum insulinlike growth factor I reference values for an automated 
chemiluminescence immunoassay system: results from a multicenter study. Hormone Research 200360 53-60. (doi:10.1159/ $000071871)$

25 Landin-Wilhelmsen K, Wilhelmsen L, Lappas G, Rosen T, Lindstedt G, Lundberg PA \& Bengtsson BA. Serum insulin-like growth factor I in a random population sample of men and women: relation to age, sex, smoking habits, coffee consumption and physical activity, blood pressure and concentrations of plasma lipids, fibrinogen, parathyroid hormone and osteocalcin. Clinical Endocrinology 1994 41 351-357. (doi:10.1111/j.1365-2265.1994.tb02556.x)

26 Svensson J, Johannsson G \& Bengtsson BA. Insulin-like growth factor-I in growth hormone-deficient adults: relationship to population-based normal values, body composition and insulin tolerance test. Clinical Endocrinology 199746 579-586. (doi:10. 1046/j.1365-2265.1997.1851001.x)

27 Duque G \& Troen BR. Understanding the mechanisms of senile osteoporosis: new facts for a major geriatric syndrome. Journal of the American Geriatrics Society 200856 935-941. (doi:10.1111/j. 1532-5415.2008.01764.x)

28 Holmer H, Svensson J, Rylander L, Johannsson G, Rosen T, Bengtsson BA, Thoren M, Hoybye C, Degerblad M, Bramnert M, Hagg E, Engstrom BE, Ekman B, Thorngren KG, Hagmar L \& Erfurth EM. Fracture incidence in GH-deficient patients on complete hormone replacement including GH. Journal of Bone and Mineral Research 200722 1842-1850. (doi:10.1359/jbmr. 070811)
29 Kanis JA. Diagnosis of osteoporosis and assessment of fracture risk. Lancet 2002359 1929-1936. (doi:10.1016/S0140-6736(02) 08761-5)

30 Melton LJ III, Atkinson EJ, O'Fallon WM, Wahner HW \& Riggs BL. Long-term fracture prediction by bone mineral assessed at different skeletal sites. Journal of Bone and Mineral Research 1993 8 1227-1233. (doi:10.1002/jbmr.5650081010)

31 Fink HA, Milavetz DL, Palermo L, Nevitt MC, Cauley JA, Genant HK, Black DM, Ensrud KE \& Fracture Intervention Trial Research G . What proportion of incident radiographic vertebral deformities is clinically diagnosed and vice versa? Journal of Bone and Mineral Research 200520 1216-1222. (doi:10.1359/JBMR. 050314)

32 Eggertsen R \& Mellstrom D. Height loss in women caused by vertebral fractures and osteoporosis. Upsala Journal of Medical Sciences 2007112 213-219. (doi:10.3109/2000-1967-195)

$33 \mathrm{Xu} \mathrm{W}$, Perera S, Medich D, Fiorito G, Wagner J, Berger LK \& Greenspan SL. Height loss, vertebral fractures, and the misclassification of osteoporosis. Bone $2011 \mathbf{4 8} 307-311$. (doi:10.1016/ j.bone.2010.09.027)

Received 15 December 2011

Revised version received 29 January 2012

Accepted 8 February 2012 